\title{
Studiemateriaal
}

\section{Discipline anatomie / embryologie}

\author{
F.M.M. Griffioen, J. Drukker, M. Godschalk, B. Hillen, P.V.J.M. Hoogland
}

\section{Besproken studiemateriaal}

\author{
1. Sobotta Atlas van de Menselijke Anatomie, R. Putz, R. Pabst \\ 2. Wolf-Heidegger's Atlas of Human Anatomy, P. Köpf-Maier \\ 3. Atlas of Human Anatomy, F.H. Netter \\ 4. Klinische Anatomie en Embryologie, A.H.M. Lohman, H.J. ten Donkelaar \\ 5. Clinically Oriented Anatomy, K.L. Moore \\ 6. Anatomy as a Basis for Clinical Medicine, E.C.B. Hall-Craggs \\ 7. Neuro-anatomy, Text and Atlas, J.H. Martin \\ 8. Neuro-anatomy, an Atlas of Structures, Sections and Systems, D.E. Haines \\ 9. Human Embryology, W.J. Larsen \\ 10. The Developing Human, K.L. Moore, T.V.N. Persaud
}

\section{Inleiding}

Voor studenten geneeskunde zijn voor het vakgebied van de anatomie en embryologie verschillende typen studieboeken nodig. Er zijn veel boeken op het vakgebied in de handel. Bij deze bespreking is de keus gemaakt voor enkele veelgebruikte studieboeken. De keuze is bepaald door de accenten die in de verschillende curricula gelegd worden en deels ook door persoonlijke voorkeuren. Voor de studenten is van belang dat zij via het studiemateriaal overzicht en inzicht in het gehele vakgebied kunnen verwerven en het studiemateriaal blijvend kunnen gebruiken om structuren op te zoeken. Voor het snel opzoeken van een structuur is het Anatomisch Zakwoordenboek van FENEIS (Bohn Stafleu Van Loghum, 3e druk, $f$ 75,-.) ook heel geschikt, maar dat heeft alle kenmerken van een woordenboek en is dus niet geschikt als studieboek. Het is daarom buiten beschouwing gelaten.

\section{Atlas}

Voor een vakgebied waarin visuele aspecten van zo grote betekenis zijn, zijn illustraties en derhalve een anatomische atlas belangrijk om te kunnen studeren. De hier besproken drie algemene atlassen zijn evenals vele andere opgebouwd uit gekleurde tekeningen met vaste kleuren voor de verschillende structuren.
Er bestaan ook atlassen die zijn samengesteld uit foto's van anatomische preparaten. Dit laatste type atlas mist de didactische duidelijkheid die voor studenten noodzakelijk is. Alle drie de atlassen zijn geschikt voor gebruik tijdens en ook na de studie geneeskunde. De keuze kan worden bepaald door persoonlijke voorkeur en de prijs. Van de SовоттA- en NetTer-atlassen zijn ook cd-romversies verkrijgbaar. Deze bieden veel extra gebruiksmogelijkheden, waaronder radiologische afbeeldingen en (zelf)testen. De beschikbaarheid van een computer op snijzalen en studieplaatsen is hiervoor wel noodzakelijk.

\section{Tekstboeken}

Er zijn nogal wat tekstboeken in de handel die refereren aan het belang van de anatomie voor de klinische geneeskunde. De wijze waarop de klinische relevantie in de boeken gestalte krijgt, varieert echter sterk: van alleen een vermelding, via bespreking in afzonderlijke kaders tot verwevenheid in de tekst. Kenmerkend voor alle Engelstalige anatomieboeken is dat het zenuwstelsel daarin nauwelijks aan de orde komt. In de Angelsaksische landen wordt dit als afzonderlijk vakgebied behandeld. Dat leidt ertoe dat in veel faculteiten gebruik gemaakt wordt van een afzonderlijk neuro-anatomieboek. 
Voor een goed inzicht in de volwassen menselijke anatomie alsmede voor het begrip over het ontstaan van congenitale afwijkingen is kennis van de embryologie een onmisbaar hulpmiddel. Op dit terrein gaan de wetenschappelijke ontwikkelingen snel, zodat het voor een leerboek van belang is dat de actualiteit gehandhaafd blijft. De hier besproken boeken beleven regelmatig een nieuwe druk, maar de toevoeging van een website aan het boek van LARSEN maakt het bijhouden van nieuwe ontwikkelingen mogelijk.

\section{Beknopte bespreking}

\section{R. Putz, R. PabST. Sobotta AtLas VAN DE MENSELIJKE Anatomie. Houten: Bohn Stafleu Van Loghum; 1994. [Atlas]}

Dit is de Nederlandse vertaling van de klassieke Duitse uitgave. Deze atlas geeft een duidelijk en volledig beeld van de anatomie van het menselijk lichaam. Ook het zenuwstelsel wordt uitgebreid behandeld. Naast de tekeningen zijn veel radiologische afbeeldingen opgenomen. De figuren zijn nauwkeurig, de kleuren zijn adequaat en de belijning is niet storend. Er zijn in deze eerste druk enkele fouten geslopen, die hopelijk als kinderziekte beschouwd kunnen worden. Voor gebruik door Nederlandstalige opleidingen heeft het boek het voordeel dat de Latijnse nomenclatuur is aangehouden. Ook het feit dat de bijschriften in het Nederlands zijn is prettig, maar niet noodzakelijk. De aanwezigheid van een Glossarium van anatomische begrippen is een niet te versmaden voordeel: veel termen zijn beter te begrijpen en te onthouden als de etymologie van de samenstellende woorden bekend is. De splitsing van het register over twee banden is onhandig: wie niet weet in welk deel van het lichaam een bepaalde structuur zich bevindt, zal vaak in beide registers moeten zoeken. Bovendien moeten beide registers geraadpleegd worden om structuren te vinden die in beide banden voorkomen.

\section{P. KÖPF-MAIER. WOLF-HEIDEGGER'S ATLAS OF Human ANATOMy. BASEL: KARGER; 1999. [Atlas]}

Deze atlas behandelt de volledige menselijke anatomie, inclusief de anatomie van het zenuwstelsel. De figuren zijn duidelijk, maar de kleuren zijn enigszins vaal. De belijning is niet storend en de namen van structuren zijn zodanig gedrukt dat het eenvoudig is ze te bedekken tijdens het studeren. Er is veel radiologisch materiaal aanwezig. In veel gevallen zijn radiologisch materiaal, tekeningen en/of doorsneden naast elkaar geplaatst zodat de student een goed inzicht krijgt in wat er in de radiologische afbeeldingen te zien is. De Latijnse nomenclatuur is aangehouden, een voordeel voor de Nederlandse student, maar de bijschriften zijn in het Engels en het Duits. In ieder deel is het totale register over beide delen afgedrukt, met een verwijzing naar het deel waar een bepaalde structuur te vinden is.

\section{F.H. NetTer. AtLas of Human ANATOMY. Summit, NEW JERSEY: CIBA-GEIGY; 1997. [Atlas]}

In deze atlas ligt de nadruk op de klinisch relevante aspecten van de anatomie. In dit kader passen de didactisch sterke schema's en de anatomische variaties die getoond worden. Het centrale zenuwstelsel wordt wat summier behandeld. De gebruikte kleuren zijn duidelijk en functioneel gericht; het gebruikte kleurengamma is een kwestie van smaak en de belijning is relatief zwaar aangezet. Voor sommige gebruikers oogt de atlas dan ook als een 'glossy magazine'. Het gebruik van de Engelse nomenclatuur sluit goed aan bij die in Engelstalige studieboeken, maar is vooral voor beginnende studenten een vaak onderschat probleem. Een groot voordeel is dat de atlas uit één band bestaat, hetgeen het opzoeken en de overzichtelijkheid zeer ten goede komt. Een belangrijk bijkomend voordeel is de in vergelijking met andere atlassen lage prijs, die overigens wel afhankelijk is van de dollarkoers.

\section{A.H.M. LOHMAN, H.J.TEN DONKELAAR. KLINISCHE ANATOMIE EN EMBRYOLOGIE. UTRECHT: ELSEVIER/BUNGE; 1997. [Algemeen tekstboek]}

De opzet van dit boek is nogal klassiek en meer op volledigheid gericht dan op didactische kwaliteit. Het grote voordeel van dit boek is het 'alles in een' karakter, dat de integratie van de verschillende aspecten van het vakgebied ten goede komt. Tevens betekent dit een belangrijke financiële besparing voor de studenten. Voor de Nederlandstalige studenten is de taal en de nomenclatuur een belangrijk voordeel. De opzet met een hoofdstuk systematische anatomie, gevolgd door hoofdstukken waarin per regio eerst de ontwikkeling, daarna de macro- 
scopische anatomie en de klinische toepassingen aan de orde komen, is goed. De inhoud van de paragrafen over de ontwikkeling zou geactualiseerd moeten worden naar de moderne inzichten, alvorens het als volwaardig embryologieleerboek beschouwd kan worden. Met een compactere stijl en het aanbrengen van meer accentuering in de tekst zou het boek zeker aan didactische kwaliteit kunnen winnen.

\section{K.L. MOORE. CLINICALLY ORIENTED ANATOMY. BALTIMORE: LIPPINCOTT, WILLIAMS \& WILKINS; 1992. [Algemeen tekstboek]}

Het boek is vooral een beschrijvend anatomieboek, waarin tussen de tekst klinische relevantie op blauwe achtergrond is weergegeven. Aan het einde van elk hoofdstuk staan enkele casus met een bespreking van de antwoorden. Door de overigens klassieke opzet en de verhalende stijl, waarbij tevens naar volledigheid gestreefd wordt, is het voor studenten vaak gemakkelijker het boek als naslagwerk dan als eerste kennismaking met de stof te gebruiken.

\section{E.C.B. HALL-CRAGGS. ANATOMY AS A BASIS FOR CLINI- CAL MEDICINE. BALTIMORE: LIPPINCOTT, WILLIAMS \& WILKINS; 1995. [Algemeen tekstboek]}

In dit boek is gekozen voor een sobere, basale aanpak van de macroscopische anatomie. Door de stijl en de veelvuldige verwijzing naar klinische relevantie is het een helder en overzichtelijk boek dat geschikt is voor de artsopleiding. De oppervlakteanatomie komt nauwelijks aan de orde. De gerichtheid op de anatomische kennis die nodig is voor het lichamelijk onderzoek en de klinische toepassing, maakt het wellicht minder geschikt voor andere opleidingen in de gezondheidswetenschappen.

\section{J.H. MARTIN. NEUROANATOMY. MAaRSSEN: ELSEVIER; 1996. [Neuroanatomie]}

Na enige inleidende hoofdstukken worden in dertien hoofdstukken functionele systemen binnen het centrale zenuwstelsel beschreven. Elk hoofdstuk toont in fotografische afbeeldingen uitwendig aanzicht en coupes van de toepasselijke hersendelen. De klinische implicaties van de beschreven morfologie worden steeds aangegeven. Hoewel de afbeeldingen in meerderheid van klassiek morfologische aard zijn, geven ze toch een goede leidraad voor de interpretatie van de resultaten van de moderne beeldvormende technieken. Het boek is vooral aan te raden aan diegenen die zich werkelijk willen verdiepen in de morfologische basis van functie en functiestoornissen van het brein.

\section{D.E. Haines. NEUROANATOMY, an AtLAS OF Structures, SECTIONS AND Systems. BALTIMORE: LIPPINCOTT, WILLIAMS \& WILKINS; 2000. [Neuroanatomie]}

In deze atlas worden de structuren van het centrale zenuwstelsel op verschillende wijzen afgebeeld. Elk van de ongeveer dertig systeembeschrijvingen gaat vergezeld van een paragraaf 'Clinical correlations' waarin het verband tussen letsels en functiestoornissen wordt aangegeven en besluit met een beschrijving van de vascularisatie van het betreffende systeem. Het boek is zeer volledig en is vooral geschikt voor zowel studenten die zich in het zenuwstelsel willen verdiepen, als voor (aanstaande) neurologen.

\section{W.J. LARSEN. HUMAN EMBRYOLOGY. NEW YORK: CHURCHILL LIVINGSTONE INC.; 1997. [Embryologie]}

Ieder hoofdstuk van dit aantrekkelijk ogende boek begint met een samenvatting; daarna volgt een in paragrafen verdeelde beschrijving. De hoofdstukken worden besloten met een sectie klinische toepassingen en een sectie experimentele principes. Tevens zijn door het vet afdrukken van de besproken termen veel accenten in de tekst aangebracht, hetgeen de bestudering ten goede komt. Er zijn veel fraaie illustraties. In het voorwoord wordt verwezen naar de website, waarop recente ontwikkelingen, animaties en zelftesten toegankelijk zijn. Deze waardevolle aanvulling maakt zowel het inzicht in de driedimensionale ontwikkeling als het bijhouden van de stand van de wetenschap op eenvoudige, moderne en aantrekkelijke manier mogelijk.

\section{K.L. Moore, T.V.N PERSAUD. THE DEVELOPING Human. Philadelphia: W.B. Saunders Comp.; 1998. [Embryologie]}

In dit boek zijn de klinische toepassingen in blauwpaarse kaders tussen de tekst verspreid. Aan het einde van ieder hoofdstuk worden klinisch georiënteerde vragen geformuleerd, die teruggrijpen op de eerdere voorbeelden en daardoor weinig uitdaging tot zelf zoeken bevatten. Er zijn veel illustraties, de kwaliteit daarvan lijkt echter eerder af dan toe te nemen naarmate de uitgave recenter is. 
De auteurs:

Dr. F.M.M. Griffioen is universitair hoofddocent, Afdeling Anatomie en Embryologie, AMC, Amsterdam. Prof. dr. J. Drukker is emeritus hoogleraar Anatomie en Embryologie aan de Universiteit Maastricht.

Dr. M. Godschalk is wetenschappelijk onderzoeker, Afdeling Anatomie en Embryologie Erasmus Universiteit Rotterdam.
Prof. dr. B. Hillen is hoogleraar Anatomie en Embryologie aan het Universitair Medisch Centrum Utrecht.

Dr. P.V.J.M. Hoogland is universitair hoofddocent Afdeling Anatomie en Embryologie, Vrije Universiteit.

\begin{tabular}{|c|c|c|c|c|c|c|c|c|c|c|}
\hline \multirow[b]{2}{*}{ Beoordeelde kenmerken* } & \multicolumn{3}{|c|}{ Atlas } & \multicolumn{3}{|c|}{$\begin{array}{l}\text { Algemeen } \\
\text { tekstboek }\end{array}$} & \multicolumn{2}{|c|}{$\begin{array}{l}\text { Neuro- } \\
\text { anatomie }\end{array}$} & \multicolumn{2}{|c|}{$\begin{array}{c}\text { Embryo- } \\
\text { logie }\end{array}$} \\
\hline & 1 & 2 & 3 & 4 & 5 & 6 & 7 & 8 & 9 & 10 \\
\hline Relevantie voor de artsopleiding & 3 & 4 & 4 & 3 & 4 & 4 & 4 & 4 & 4 & 4 \\
\hline $\begin{array}{l}\text { Relevantie voor medische biologie/ } \\
\text { gezondheidswetenschappen }\end{array}$ & 3 & 3 & 4 & 3 & 3 & 4 & 3 & 3 & 4 & 4 \\
\hline Inhoudelijke kwaliteit & 4 & 4 & 3 & 4 & 4 & 3 & 5 & 5 & 4 & 3 \\
\hline Vormgeving & 4 & 3 & 3 & 4 & 3 & 3 & 4 & 4 & 4 & 3 \\
\hline Didactische kwaliteit ('studeerbaarheid') & 3 & 3 & 4 & 3 & 3 & 4 & 5 & 5 & 4 & 4 \\
\hline Geschikt als verplichte zelfstudiestof & 3 & 3 & 4 & 3 & 3 & 4 & 4 & 4 & 3 & 3 \\
\hline $\begin{array}{l}\text { Kwaliteit verwijssystematiek en } \\
\text { dekking van de materie }\end{array}$ & 4 & 4 & 3 & 4 & 4 & 3 & 5 & 5 & 4 & 4 \\
\hline Aan te bevelen om zelf aan te schaffen & 4 & 4 & 3 & 4 & 4 & 3 & 5 & 5 & 4 & 4 \\
\hline Geschiktheid voor de gehele studie & 4 & 4 & 3 & 4 & 4 & 3 & 5 & 5 & 4 & 4 \\
\hline Kwaliteit voorbeelden/casus & 4 & 4 & - & 4 & 4 & - & - & - & 4 & 4 \\
\hline Kwaliteit studieopdrachten of vragen & - & - & - & - & - & - & - & - & - & 3 \\
\hline $\begin{array}{l}\text { Kwaliteit antw. bij studieopgaven } \\
\text { of vragen }\end{array}$ & - & - & - & - & - & - & - & - & - & 4 \\
\hline \multicolumn{11}{|l|}{ Beschrijvende kenmerken } \\
\hline Taal & N & E & $\mathrm{E}$ & N & $\mathrm{E}$ & $\mathrm{E}$ & $E$ & $E$ & $E$ & E \\
\hline Omvang in pagina's & 821 & 822 & 611 & 107 & 917 & 587 & 578 & 256 & 512 & 563 \\
\hline $\begin{array}{l}\text { Omvang (breedte maal hoogte, } \\
\text { afgerond in } \mathrm{cm} \text { ) }\end{array}$ & $20 \times 27$ & $22 \times 29$ & $22 \times 29$ & $19 \times 27$ & $22 \times 28$ & $19 \times 27$ & $21 \times 28$ & $23 \times 30$ & $20 \times 25$ & $22 \times 28$ \\
\hline Aantal delen & 2 & 2 & 1 & 1 & 1 & 1 & 1 & 1 & 1 & 1 \\
\hline Druk & 20 & 5 & 2 & 1 & 3 & 3 & 2 & 5 & 2 & 6 \\
\hline Jaar van uitgave & 1994 & 1997 & 1999 & 1997 & 1992 & 1995 & 1996 & 2000 & 1997 & 1998 \\
\hline Jaar van eerste druk & 1904 & 1954 & 1989 & 1997 & 1980 & 1985 & 1989 & 1983 & 1993 & 1973 \\
\hline Prijs (in guldens) & 326 & 234 & 170 & 165 & 135 & 127 & 130 & 87 & 127 & 106 \\
\hline
\end{tabular}

Beoordeling: 1= zeer slecht/zeer gering/zeer ongeschikt; 2 =slecht/gering/ongeschikt; $3=$ matig; 4 = goed/groot/geschikt; $5=$ zeer goed/zeer groot/zeer geschikt 